\title{
HEART DISEASE IN SCLERODERMA
}

\author{
BY \\ D. W. BARRITT AND W. O'BRIEN \\ From Charing Cross Hospital \\ Received October 15, 1951
}

The lesions of scleroderma are now recognized to be widespread throughout the body. The œsophagus, the gastro-intestinal tract, and lungs are commonly involved besides the skin and muscles. The nerves and central nervous system, the endocrine glands, bones, joints, and the mouth (the tongue and palate) may also be affected. Pathological changes in the heart muscle have long been recognized at necropsy in these cases, but clinical signs of cardiac involvement appear to be rare. Heine in 1926 was the first to describe such a case; Weiss in 1943 collected nine cases, whilst Mathison and Palmer (1947) in America and East and Oram (1947) in this country have each described a case.

\section{CASE RePORTS}

Case 1. A single woman, aged 50 years, working as a dressmaker developed herpes zoster in 1946 and following this never regained her previous good health and began to notice for the first time breathlessness on exertion. In 1948 the typical lesions of scleroderma appeared spreading to involve the hands, arms, face, buttocks, and legs and this was accompanied by conspicuous general muscular weakness. In the beginning of 1951 this breathlessness increased so that she would have to stop and look into shop windows to recover while walking. In April, 1951, swelling of both ankles appeared. She was admitted into Charing Cross Hospital in May.

On admission it was found that there were widespread sclerodermatous skin lesions with heavy pigmentation involving the hands, arms, face, buttocks, and legs with scars of recent small ulcerations on the tips of the fingers (Fig. 1). The jugular venous pressure was considerably raised, there were rales at both lung bases, the free margin of the liver was felt at the level of the umbilicus, and the legs and sacrum were odematous. The pulse rate was 100 a minute, the rhythm regular and no pulsus paradoxus was detected. The apex beat was displaced far out and was moderately vigorous; the first heart sound was widely split at the apex and the second heart sound widely split at the base; there were no murmurs. The blood pressure was $155 / 80$.

Radioscopy showed the heart to be greatly enlarged and triangular in shape, with little movement (Fig. 3). The appearances were suggestive of a pericardial effusion whilst a kymogram confirmed the lack of movement of the ventricles. An X-ray of the hands showed calcinosis of the fingers (Fig. 4). The electrocardiogram revealed depression of the $S-T$ segment over the left ventricular leads with flat $\mathrm{T}$ waves. The S-T segments from V2 to V4 were elevated with the concavity of the curve upwards (Fig. 2).

The temperature remained normal. The E.S.R. was $80 \mathrm{~mm}$. in the first hour. No fluid was obtained from the pericardium though paracentesis was twice attempted.

Laboratory investigations. Blood examination: hæmoglobin 11.4 g. W.B.C., 3600; polymorphs, 79 per cent. No eosinophils were found in $1 \mathrm{c.mm}$. of blood. Plasma proteins, 8.4 per $100 \mathrm{ml}$. (albumin, 3.9; globulin, 4.5). Sodium, 324; chlorides, 609; calcium, 8.7 (mg. per $100 \mathrm{ml}$.). Pyruvate levels within normal range. Urinary creatinine, $3.9 \mathrm{~g}$; creatine, $4.5 \mathrm{~g}$. per $100 \mathrm{ml}$. 
Skin and muscle biopsy report. "The sections of the skin showed increased fibrosis of the dermis and collections of plasma cells and eosinophils. The muscle showed slow necrosis with fibrous replacement. The condition appeared to be dermatomyositis."

Progress. The patient was treated with digitalis and neptal and with salt and water restriction, and in the first three weeks her œdema subsided and the jugular venous pressure fell, though it remained raised. In the hope of influencing the sclerodermatous process a course of A.C.T.H. was begun and she was given $25 \mathrm{mg}$. four times daily for twelve days. The dose was later reduced to $15 \mathrm{mg}$. four times daily for twenty-five days. The eosinophil count showed a satisfactory response. Within a few days of starting A.C.T.H. therapy she felt better, her muscular strength 


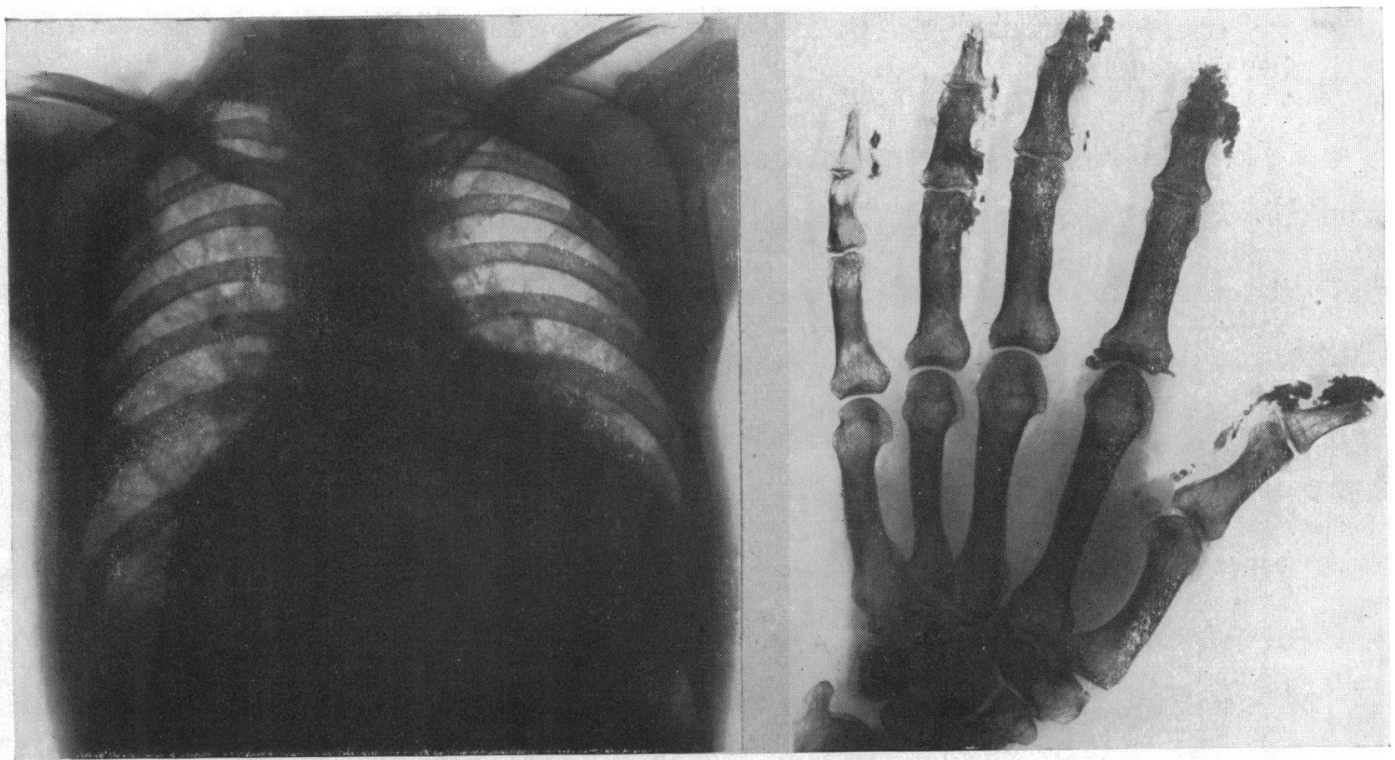

FIG. 3.-Case 1. Teleradiogram in scleroderma heart disease.

Fig. 4.-Case 1. X-ray of hands showing atrophy of terminal phalanges and calcinosis.

was a little greater and the limitation of movement of the elbows was reduced though not abolished. As hormone therapy ceased, the jugular venous pressure was still raised and rales were heard at the lung bases. A week later, however, the venous pressure had fallen to normal, the lung bases were clear, and congestive failure was considered no longer to be present. This result was not unexpected in view of the salt and water retention effect of A.C.T.H. A great improvement was evident in the general condition of the patient. She began to walk again; the skin of the face lost much of its pigmentation and she was able to begin to knit.

The electrocardiogram was unchanged. There was no significant change in the size and shape of the heart.

Case 2. A housewife of 44 years had symptoms for seven years. She first noticed weakness of the arms with discoloration and tightening of the skin. The ankles began to swell and there were wide-spread pains in the limbs and trunk. For six years flexion deformities of the knees had prevented her from walking. In the last three years her condition had improved rather than deteriorated and she was able to move about the room on a wheel stool. Her mother had been a diabetic.

Clinical examination showed classical sclerodermatous lesions of the arms, neck, trunk, and legs. There were flexion deformities of both elbows and knees with considerable muscular weakness. The pulse was regular, and of normal volume. B.P., 130/70. The cardiac impulse was not displaced and was of normal left ventricular type. The first and second heart sounds were normal at the apex and base. The jugular venous pressure was not raised. The lung bases were clear. The urine contained glucose.

Radioscopy showed a normal cardiac silhouette, and the barium swallow was normal. The cardiogram showed inversion of the T waves in leads V1 to V4 (Fig. 5).

The following pathological data were obtained: Glucose tolerance curve was of the diabetic type. Urinary creatine was $70 \mathrm{mg}$ per $100 \mathrm{ml}$. Creatinine was $37 \mathrm{mg}$. per $100 \mathrm{ml}$.

Progress. The patient's condition was slowly improving and it was not felt justified to subject her to A.C.T.H. therapy. The diabetes was known to have been of recent onset and responded 
satisfactorily to a low carbohydrate diet. The presence of a family history of diabetes made it unlikely that sclerodermatous fibrosis of the pancreas was responsible for her glycosuria.

\section{Discussion}

The coincidence of cardiac failure and scleroderma does not prove that they are related but in these cases the evidence for such an assumption is strong. The absence of a history of rheumatism, chorea, or anginal pain, the absence of signs of a valvular lesion in the heart, of hypertension, of thyroid disease, of anæmia, of pulmonary disease, or of vitamin B deficiency ruled out anything but a rare cause of the congestive failure. In reports of necropsies in this condition gradual replacement of the heart muscle fibres with fibrous tissue without evidence of an inflammatory reaction appears to be the basic lesion. The subepicardial muscle is the region most affected and the fibrosis may extend to the subepicardial fat and subepicardial connective tissue. A variable pericardial effusion may be found and a chronic fibrous pericarditis was present in Bevan's case (1945). In the first case, progressive cardiac failure in normal rhythm associated with a characteristic triangular shape of the heart, and lack of ventricular movement, with non-specific electrocardiographic changes suggested pericardial involvement. This may be the usual picture. These were two of four cases of generalized scleroderma present in the hospital at the same time suggesting that cardiac involvement is by no means rare.

A.C.T.H. produced a general improvement in Case 1, and congestive heart failure was relieved when a long period of rest, dieting, and medication had been only partially successful. It is clearly justifiable to administer this compound in scleroderma heart disease provided proper precautions are taken to prevent sodium and water retention.

\section{SUMMARY}

Two cases of scleroderma heart disease are described. Reference is made to the apparent rarity of severe circulatory changes in this condition. Congestive heart failure was present in one of the cases. Treatment with A.C.T.H. did not produce any remarkable change in the heart condition.

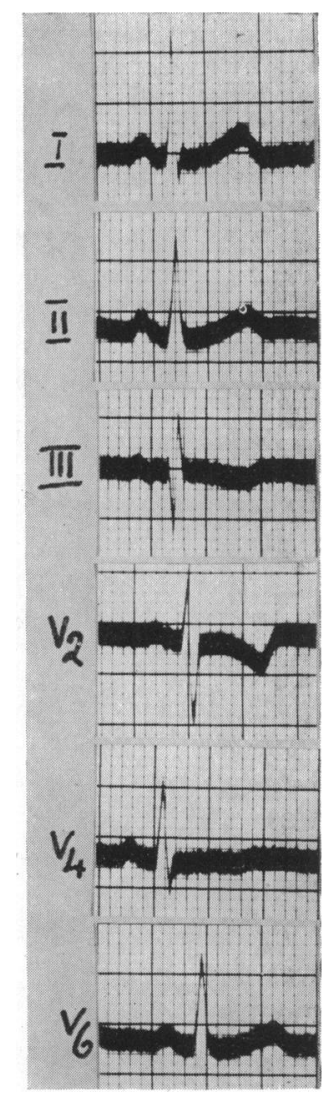

FIG. 5.-Case 2. Cardiogram in scleroderma heart disease.

We wish to thank Dr. R. A. Hickling and Dr. K. Shirley Smith for permission to study their cases.

\section{REFERENCES}

Bayles, T. B., Stout, C. F., Stillman, J. S., and Lever, W. (1950), Proc. First Clin. A.C.T.H. Conf., 447.

Bevan, M., (1945). Amer. J. Path., 21, 25.

East, T., and Oram, S. (1947). Brit. Heart J., 9, 167

Goetz, R. H. (1945). Clin. Proc. Capetown Postgrad. Med. Ass., 4, 337.

Heine, J. (1926). Virchows Arch., 262, 351.

Mathison, A. K., and Palmer, J. D. (1947). Amer. Heart J., 33, 366.

Weiss, S., Stead, E. A., Warren, J. V., and Bailey, O. T. (1943). Arch. intern. Med., 71, 749. 